\title{
O que submete e o que é submetido: variações em Butler e Atwood
}

\author{
Anunciata SaWAda \\ Museóloga e professora, Esp. em Ciência das \\ Artes, Museu da Vida, FIOCRUZ.
}

\section{LUCIA DE LA ROCQUE}

$\mathrm{PhD}$, pesquisadora e professora do Instituto Oswaldo Cruz, FIOCRUZ e do Instituto de Letras, UERJ.
Resumo: No presente artigo, é nosso objetivo esboçar uma breve análise de duas obras de ficção científica, o romance The Handmaid's Tale (sendo que o título da última ediçăo brasileira é 0 Conto da Aia), de 1985, da escritora canadense Margaret Atwood, e o conto "Bloodchild" de 1987. da autora afro-americana Octavia Butler, traçando um paralelo entre as mesmas. Ambas as obras tratam da questâo feminina, evidenciando que questōes como a maternidade e a reprodução estāo intimamente ligadas ao fator que mais caracteriza a situação que se propōem a descrever: a submissāo, cuja realidade é também magistralmente espelhada nessas ficçōes.

Palavras-chave: Fiç̧ão cientifica; gênero; submissão.
Abstract: It is our aim, in the present paper, to carry out a brief analysis of two science fiction works, the novel The Handmaid's Tale (1985), by Canadian writer Margaret Atwood, and the tale "Bloodchild"(1987), by Afro - American author Octavia Butler. Both works bring to light the female question, evincing that questions such as motherhood and reproduction are closely linked to the factor that more strongly characterizes the situation they propose to describe: the issue of submission, the reality of which is also masterfully displayed in these fictions.

Key-words: Science fiction, gender, submission. 


\section{Introdução}

Feminino e masculino são uma polaridade desequilibrada. Direitos iguais para os homens nunca foram inspiração para uma marcha de protesto ou uma greve de fome. Em nenhum país do mundo os homens são considerados legalmente incapazes, como ocorreu com as mulheres de várias nações européias até o século XX e ainda ocorre em vários países muçulmanos, do Marrocos ao Afeganistão. Nenhum país deu o direito de voto primeiro às mulheres para só depois concedê-lo aos homens. Ninguém jamais pensou que os homens fossem o segundo sexo. (SONTAG, 2000, p.9).

O objetivo deste artigo é esboçar uma breve análise de duas obras de ficção científica, o romance The Handmaid's Tale, de 1985, (sendo que o título da última edição brasileira é O Conto da Aia) da escritora canadense Margaret Atwood, e o conto "Bloodchild"' de 1984, da autora afro-americana Octavia Butler, com a intenção de traçar um paralelo entre as mesmas. Haveria, logicamente, infinitas possibilidades de aproximações entre o livro de Atwood, obra que, ao mesmo tempo em que se tornou um best seller, não deixou de ser recebida com louros pela crítica especializada ${ }^{2}$, e o conto de Butler que, embora certamente muito mais restrito ao círculo de admiradores da ficção científica, foi excepcionalmente aclamado dentro desse gênero literário. ${ }^{3}$ Nosso recorte, no entanto, se apoiará em nossa crença em que ambas as obras tratam da questão feminina naquilo que mais caracteriza a situação que se propõem a descrever: a submissão, cuja realidade é também magistralmente espelhada nas mesmas.

Conforme mencionamos, temos plena consciência de que a ficção científica é um gênero que ainda não desfruta de muita visibilidade no campo literário; no entanto, esse gênero tem inegavelmente recebido, nos últimos tempos, uma injeção de considerável prestígio. Desde os anos 70, estudos como o de Robert Scholes defendem a literatura cujo imaginário se
${ }^{1}$ Uma traduçāo deste conto foi feita para a língua portuguesa e saiu publicada na Isaac Asimov Magazine número 21 de 1992 , com o título "Os Hospedeiros".

\section{${ }^{2}$ The Handmaid's Tale} recebeu dois prêmos: o Governor General ‘s, no ano de sua publicação, e o Arthur C. Clarke, em 1987, ano em que foi instituído. Foi também indicado para os famosos prêmios Booker e Nebula este último sendo concedido especificamente a obras de ficção científica desde 1965.

3 "Bloodchild" foi premiado com o Nebula e o Hugo (prêmio também específico para obras de ficção científica) em 1985. 
projeta no futuro, afirmando que ela é extremamente relevante não só quando alerta sobre a consequência de ações ainda não realizadas, mas quando "nos faz sentir essas consequências, em nossos corações e nossas vísceras" (SCHOLES, 1975, p. 16). O olhar positivo sobre esse gênero literário tem perdurado e, bem mais recentemente, Tom Moylan argumenta que "o famoso 'escapismo' atribuído à ficção científica não implica necessariamente numa fuga da realidade que aliena, mas também pode levar a um escape que fortalece e que faz refletir, para uma maneira muito diferente de pensar o mundo, e possivelmente de se situar no mundo" (MOYLAN, 2000, p. 5). E também Moylan afirma que a maior contribuição teórica no campo da ficção científica tem vindo da esfera feminista. Uma das maiores expoentes dessa esfera, Marleen Barr, afirma: "A ficção científica feminista fornece esquemas para estruturas sociais que possibilitam que palavras de mulheres oponham-se a mitos patriarcais" (BARR, 1993, p. 7). Acreditamos que as ficções aqui trabalhadas se encaixam como uma luva nessas palavras de Barr. No entanto, para uma análise mais completa, não podemos deixar de mencionar que outras obras das referidas autoras, sejam elas de ficção científica ou não, também tangenciam este quadro em que a mulher é colocada em destaque.

As narrativas analisadas no presente trabalho giram em torno das relações interpessoais, lidando com o fato de as protagonistas, sejam elas de nossa espécie ou não, demonstrarem reações diferentes (ficção ou não, "la donna è mobile" - e não o é todo ser humano, fato que o chauvinismo da ópera de Verdi jamais acataria...) mediante a situação em que se encontram a cada momento. As duas obras aqui enfocadas trazem em seu bojo algumas questões essenciais, tais como: a maternidade, a reprodução, o multiculturalismo racial e a relação de tudo isso com o gênero que, por mais que a circundemos, está sempre imbuída pelo paradigma da submissão. Passaremos, a seguir, a nos debruçar sobre a figura feminina nas obras estudadas e, para evidenciar as especificidades historicamente atribuídas às mulheres, citamos o poeta cômico Podisipo, que no século III, ao discorrer sobre a 
pertinência de manter-se um filho ou uma filha, disse: "Um filho sempre se cria; uma filha abandona-se mesmo quando se é rico" (MAFFRE, 1989, p. 11).

\section{Duas autoras e as variações em torno de um tema}

Os gregos desaprovavam atitudes de avassalamento, ativas ou passivas, em todas as esferas de relação que tinham a Poliscomo cenário (VERNANT, 1994): esse é um consenso dos helenistas contemporâneos. Assim, tendo como pano de fundo a questão feminina de jugo e submissão, analisaremos as óticas em que Atwood e Butler desenvolvem seus modelos narrativos, que não podem deixar de estar, de alguma forma, impregnados por suas origens socioeconômicas, étnicas, enfim, socioculturais como um todo.

Margaret Atwood nasceu em 1939, na cidade de Ottawa, Canadá. Filha de um entomologista, passou boa parte de sua infância em contato com a natureza em sua terra. Tornou-se uma das mais renomadas escritoras canadenses. Sua obra não se restringe somente à literatura de ficção, tendo uma importante produção no campo da poesia, crítica literária e literatura infantil.

O Conto da Aia, publicado como The Handmaid's Tale em 1985, é uma obra com claras características distópicas.

O termo "distopia", entendido como antônimo de 'utopia', foi cunhado em 1868 pelo filósofo e político britânico John Stuart Mill, entrando aos poucos na linguagem corrente - primeiro nos países de língua inglesa - a partir de 1952 (CARDOSO, 2006, p. 30)

Se, num primeiro momento, Mill usou seus conhecimentos de grego para caracterizar o novo termo que estava usando, como "lugar mau", sendo que utopia significa "lugar nenhum", esta definição sofre uma adaptação natural, passando a ser considerada como o antônimo de utopia. Desta forma, encontramos no romance de Atwood o quadro pertinente ao que 
poderíamos chamar de um cenário distópico: a desesperança, os dilemas e embates morais com todos os meandros mais sutis da personalidade humana e, acima de tudo, uma sociedade opressora, capturando os direitos mais fundamentais de liberdade e expressão de seus membros. Todo esse horror é justificado, em parte, pela altíssima taxa de infertilidade provocada por acidentes nucleares, e desastres ecológicos, quadro típico das distopias da segunda metade do século XX (BOOKER, 1994; HAYNES, 1994), assim como doenças sexualmente transmissíveis, claramente inspiradas no flagelo em que se constitui a deflagração da AIDS no começo dos anos 80 .

A conservadora República de Gilead, onde a Aia terá sua história desenrolada, é um Estado autoritário, controlado por homens de estrita formação cristã, direcionando a vida de seus membros com interpretações fundamentalistas da religião e de seu livro sagrado, a Bíblia.

Uma forma vermelha, uma touca de abas brancas ao redor da cabeça, uma forma como a minha, uma mulher de aparência sem graça e desinteressante, de vermelho, carregando uma cesta, se aproxima da calçada de tijolos vindo em minha direção. Ela me alcança e examinamos uma o rcsto da outra, olhando pelos túneis brancos de tecido que nos cercam. Ela é a mulher certa.

- Bendito seja o fruto - diz ela para mim, a expressão de cumprimento considerada correta entre nós.

- Que possa o Senhor abrir - respondo, a resposta também correta. Viramo-nos e caminhamos juntas passando pelas grandes casas, em direção à parte central da cidade. (ATWOOD, 2006, p. 29)

A função das Aias é serem "úteros bípedes", como definem as "Tias", mulheres mais velhas que treinam as jovens, antes mulheres independentes, para essa desprezível função, que consiste em ter relações uma vez por mês com os Comandantes de Gilead - os que 
orquestraram o estabelecimento do novo regime - na presença de suas próprias esposas, sendo que a descrição dessa atrocidade nos fornece uma das cenas mais grotescas do livro. Qualquer criança que nasça dessas uniões deve ser entregue ao casal poderoso (DE LA ROCQUE, 2004). O adestramento para essa situação dantesca se dá em "Centros" que combinam a atmosfera de dormitório de estudantes com a de um cárcere. $\mathrm{O}$ uso degradante dessas moças é justificado pelo relato bíblico em que Raquel, que não conseguia dar filhos a Jacó, lhe ofereceu sua serva Bala e disse que os filhos que dela nascessem lhe pertenceriam. Atwood, aliás, deixa bem claro, em suas entrevistas, que, por mais que o inferno de Gilead soe exagerado, todas as práticas nele perpetradas já ocorreram em diversos momentos históricos através do planeta (INGERSOL, 1990).

A figura feminina tem um papel quase paradoxal: é ao mesmo tempo importante e secundária, submissa e submetida a um enquadramento em classes, verdadeiras castas, cujos critérios de escolha são determinados pelos homens, segundo certos ditames que encontram semelhanças entre as figuras bíblicas e certas figuras das antigas histórias infantis, notadamente Chapeuzinho Vermelho, por conta de fatores como a cor dos hábitos das Aias, e obviamente a associação dos Comandantes à figura do Lobo Mau (WILSON, 1996).

Ao lado disso, existe a preocupação com o viés econômico; nessa distopia, só a fina flor da hierarquia gileadeana, os Comandantes, têm direito às Aias, os outros tendo que se contentar apenas com as próprias esposas, ironicamente chamadas "Economoesposas". No pesadelo feminista que é a República de Gilead, a leitura e a escrita estão proscritas para todas as mulheres, até mesmo para as Esposas dos Comandantes. No entanto, é inegável que a opressão atinge de forma mais acirrada as Aias. A essas moças não é permitido nem mesmo o que caracteriza e individualiza não somente seres humanos, mas até mesmo animais domésticos de estimação: um nome próprio. 
${ }^{4}$ Além das Tias, Esposas, Aias e Economoesposas, existem as Martas antigas empregadas domésticas, a que, logicamente só os poderosos têm acesso, e as Antimulheres, que são as antigas feministas ou as que se rebelam contra o sistema, e que passam o curto resto de suas vidas limpando lixo radioativo e tóxico em geral, sem nenhuma proteção.
Portanto, nunca ficamos sabendo o nome real da narradora. Sua denominação gileadeana, Defred, designa que ela é propriedade do Comandante Fred, e suas companheiras são Deglen, Dewarren, e assim por diante.

A categorização das mulheres em classes cujas funções eram determinantes para o funcionamento do grupo social ${ }^{4}$ ressalta a importância que tinham, já que era a partir dessa divisão que a sociedade se ajustava e garantia sua sobrevivência no quesito procriação. Se aos homens cabia a defesa e organização do Estado, dentro de criteriosos aspectos pseudomorais (haja visto que a instituição dos bordéis ou casas de diversão masculina era mantida sob o mesmo aspecto que hoje ainda persiste em nossa sociedade: falsamente secretos e obscuros) e religiosos, às mulheres cabia a manutenção social e familiar, procriando, cuidando do bem-estar da casa e garantindo que a "harmonia" imposta pelo regime seguisse em frente.

Mesmo na parte final do livro, quando é descortinada a situação enfocada, encontramos ainda, naqueles pesquisadores em cujo trabalho a recuperação da memória dos fatos estava fundamentada, notas (mesmo que veladamente) de uma posição, não tão distante, do olhar enquadrador e mesmo inquisidor da figura feminina:

Sabemos que aquela cidade era uma proeminente estação intermediária do que a autora se refere como 'A Estrada Clandestina Feminina', desde então apelidada por alguns de nossos trocistas históricos de 'A Estrada Clandestina do Sexo Frágil'. (Risos, gemidos e apupos). (ATWOOD, 2006, p 353)

De forma contígua ao perfil feminino ficcionalizado por Atwood, encontramos, na obra de Butler, "Bloodchild", um enfoque da feminilidade que permeia a questão de poder, reforçado, no entanto, pela reversão de papéis de gênero, não só no tocante ao lado social, como também, o que é sem dúvida ainda mais chocante por causar maior estranhamento, da função biológica. 
Octavia Butler (1947-2006) é, sem dúvida, a mais notável escritora afro-americana no campo da ficção científica. Órfã de pai desde muito cedo, foi criada pela mãe, que trabalhava como empregada doméstica e pela avó, e viveu toda a realidade do preconceito racial em seu meio, em Pasadena, na Califórnia, onde nasceu. Sua carreira como escritora de ficção científica começou ainda na infância e, como a própria Butler comenta: "eu não escolhi, aconteceu".

The Washington Post has called her one of the finest voices in fiction, period. A master storyteller who casts an unflinching eye on racism, sexism, poverty, and ignorance and let's the reader see the terror and the beauty of human nature.

Octavia has described herself as an outsider, a pessimist, a feminist always, a Black, a quiet egoist, a former Baptist, and an oil-and-water combination of ambition, laziness, insecurity, certainty, and drive. (GONZALES, 2005)

[O Washington Post chamou-a simplesmente de uma das vozes mais entoadas da ficção. Uma mestra em contação de histórias que lança um olhar firme sobre o racismo, o sexismo, a pobreza, e a ignorância, deixando o leitor ver o terror e a beleza da natureza humana.

Octavia descreveu a si mesma como uma outsider, uma pessimista, uma eterna feminista, uma negra, uma egoísta sossegada, uma ex-batista, e uma combinação de óleo e água de ambição, preguiça, insegurança, certeza, e ímpeto]

Bloodchild and Other Stories (sem tradução em português) é um livro de contos e ensaios de ficção científica e foi publicado em 1995. O conto "Bloodchild" foi primeiramente publicado numa coletânea de ficção científica, em 1984 e, como já dito, ganhou prêmios importantes. Embora a própria Butler alegasse que o conto em si devia-se ao seu medo de insetos e tratava 
principalmente da gravidez masculina (BUTLER, 1996), encontramos na história muito do quadro a que foram e ainda são submetidos os negros americanos, assim como os de outras nacionalidades: dominação e submissão a uma cultura maior, mais forte.

[...] seus livros transcendiam as meras características do gênero e propunham questionamentos mais profundos, envolvendo a capacidade da comunicação do ser humano e a questão da alteridade nas relações interpessoais[...]

Negra e lésbica, Butler sempre escreveu histórias em que predomina a questão do Outro e de sua invasão - uma espécie de impossibilidade de contato não porque as linguagens sejam diferentes, mas simplesmente porque não há interesse em se ouvir o que o outro tem a dizer. É a linguagem do invasor, do colonizador. (FERNANDES, 2007)

A história de "Bloodchild" se desenrola num planeta em que os humanos que lá chegaram, bem antes de o narrador - o jovem Gan, recém entrado na adolescência - nascer, fugindo de guerras e devastação na Terra (portanto, de um futuro distópico, que, como toda distopia, só faz acentuar os presentes flagelos), se deparam com habitantes nativos, os Tlic, criaturas racionais com a forma de insetos gigantes, altamente matriarcais, cujo sistema reprodutivo envolve a postura de ovos no interior de um hospedeiro vivo. Os animais semelhantes a mamíferos nativos desse mundo haviam, ao longo do tempo, desenvolvido um tipo de imunidade que resultava na destruição desses ovos, antes do processo de eclosão. A chegada dos humanos ao planeta dos Tlic provou ser extremamente benéfica para essas criaturas, já que esses imigrantes revelaram ser hospedeiros ideais para seus ovos - homens sendo preferencialmente utilizados nessa função, para que as mulheres pudessem ser poupadas para "prover a próxima 
geração de animais hospedeiros" (BUTLER, 1996, p. 21). No momento em que a história se passa, notamos que já houve uma evolução, de uma época em que os humanos eram praticamente enjaulados e tratados como meros incubadores de ovos fertilizados para um sistema social em que os Tlic "adotam" humanos em sua família. Essa situação mais favorável é, ironicamente, possibilitada pelo fato de, logo antes da eclosão das larvas, haver a liberação de substâncias venenosas na corrente sanguínea, que provocam dores lancinantes; assim, há uma forte possibilidade de as larvas serem removidas de seu hospedeiro antes que danos irreparáveis sejam causados.

O narrador Gan é um jovem humano "adotado" por T'Gatoi, uma líder política Tlic, que espera há muito que o rapaz cresça o suficiente para ser hospedeiro de sua descendência; ele estava a ela prometido desde seu nascimento, sendo que o pai de Gan havia sido hospedeiro da própria T'Gatoi (DE LA ROCQUE, 2006). O que salta aos olhos, então, é que Butler cria uma situação altamente fantástica, no entanto, familiar o suficiente para que sua história possa ser crível a ponto de nos envolvermos por ela. Não só há, de fato, animais em que o macho parece só lá estar para cumprir sua função reprodutiva ${ }^{5}$, mas também há muito se conhece a infestação de mamíferos por parasitas que se instalam na corrente sanguínea. A própria Butler, no adendo ao conto, admite que parte de sua motivação para escrever "Bloodchild" derivou de uma viagem que fez ao Peru e da "preocupação" com suas "possíveis reações a uma parte do conjunto de insetos da área”, principalmente após tomar conhecimento de um tipo de mosca "que deposita os ovos em feridas deixadas pelas picadas de outros insetos"( BU'TLER, 1996, p. 30).

A saga de humanos que fugiram da Terra devastada por problemas diversos, vivendo num planeta distante regido por insetos, nos dá uma visão da relação de troca e submissão de um grupo por outro, numa tentativa de
5 Podemos citar os vermes Loloforados, em que o macho de tamanho diminuto, vive no útero da fêmea, assim como o exemplo das aranhas, gênero em que as fêmeas são bem maiores e mais poderosas que os machos (é preciso lembrar que a classe dos aracnídeos pertence ao filo dos artrópodes, que engloba também a classe dos insetos, que os Tlic tanto lembram). 
sobrevivência de ambos. É uma dependência necessária para as duas formas de vida.

O mundo em que Gan vive, em "Bloodchild", possivelmente guarda semelhanças com o mesmo em que a autora viveu a sua infância, na Califórnia; os contornos podem ser sobrepostos quando os personagens passam a seres interdependentes. A família de Gan orgulha-se de ter T'Gatoi como um "membro". Na verdade, eram os seres do governo de Tlic (sempre fêmeas, já que os machos da espécie tinham papel exclusivamente reprodutor e uma vida bem mais curta) que escolhiam em que família humana entrar para que seus membros masculinos pudessem ser hospedeiros de suas larvas. Assim, podemos concluir que não era a família de Gan que possuía T'Gatoi, e sim o contrário. T'Gatoi era uma das oficiais de Tlic responsáveis pela preservação dos Terráqueos e seu envolvimento com a família, como já vimos, vinha de longa data.

A relação entre Gan, T'Gatoi e a família de Gan, com a trocà de benesses entre os personagens da ação, novamente nos reporta a uma situação já vista entre senhores e escravos. Muito embora, em certos momentos, pudessem existir sentimentos de afeto, ainda assim era uma relação entre dominante e dominado.

[...] afro-americanos são, num sentido muito real, os descendentes de abduzidos por aliens. Eles habitam um pesadelo sci-fi em que invisíveis, mas não menos intransponíveis campos de força de intolerância frustram seus movimentos; histórias oficiais desfazem o que a eles tem sido feito; e a tecnologia, seja ela a marcação a ferro (branding), a esterilização forçada, o experimento Tuskegee, ou tasers, é muito frequentemente trazida para afetar corpos negros. (DERY, 2007)

Não é mera coincidência, portanto, o fato de a obra de Butler encontrar-se povoada por alienígenas e outras figuras estranhas. Quando os protagonistas são 
todos humanos, frequentemente encontramos a diferença sob outras roupagens. Em "The Evening and the Morning and the Night", conto que foi publicado no mesmo volume de contos que "Bloodchild" (BUTLER, 1996ः), deparamo-nos com a mesma na "forma de uma terrível doença hereditária que a narradora e protagonista carrega dormente em seus genes, mas de uma maneira vívida em sua consciência" (DE LA ROCQUE, 2002, p. 63).

É interessante, então, notarmos o contexto em que estão inseridas as autoras citadas e de que forma essa situação social e psicológica causa influência em suas obras. Ambas foram escritas na década de 80. Ambas carregam. em seu conteúdo, diferentes visões de uma época sobre assuntos que permearam esse período. O "Conto da Aia" nitidamente espelha o conservadorismo republicano que fortemente aflorou na década e que foi ajudado pelos programas evangelizadores, veiculados pela televisão norte-americana. Os "fundamentalistas" religiosos que cerraram fileiras contra grupos minoritários, como os homossexuais, e a prática social do aborto, (prática esta punida com a morte no romance de Atwood) foram coñsequências diretas do liberalismo que grassara nas décadas anteriores e que serviu de cenário para a emancipação feminina.

The extreme shift toward conservatism in the United States at that time is significant to the social change that created the Republic of Gilead in Atwood's imagination. After the novel was published, she told an American interviewer that she had tried originally to set the novel in Canada, but that it just would not fit the Canadian culture. "It's not a Canadian sort of thing to do," she told Bonnie Lyons in 1987. "Canadians might do it after the United States did it, in some sort of watered-down version. Our television evangelists are more paltry than yours. The States are more extreme in everything." (Disponível em 
http://www.answers.com/topic/the-handmaid-stale-novel)

[A mudança extrema em direção ao conservadorismo nos Estados Unidos naquela época é significante para a mudança social que criou a República de Gilead na imaginação de Atwood. Após o romance ter sido publicado, ela disse a um entrevistador americano que, originalmente, havia tentado fixar o cenário do romance no Canadá, mas que isso não se ajustaria à cultura canadense. "Não é uma coisa que seria feita no Canadá", ela disse a Bonnie Lyons em 1987. "Os canadenses poderiam fazer isto depois que os Estados Unidos o tivessem feito, num tipo de versão diluída. Nossos evangelistas de televisão são mais insignificantes que os seus. Os Estados Unidos são mais extremos em tudo".]

Enquanto Atwood é branca, heterossexual, casada, com filhos, pertencente a uma classe social dita dominante: brancos bem situados na América do Norte, Butler é negra, lésbica, sem filhos, oriunda de uma classe social cuja trajetória é marcada por constantes lutas na tentativa de uma afirmação socioeconômica que fosse reconhecida por todos. Dessa forma, dentro do mesmo mundo, do mesmo período, "Bloodchild" é contextualizado, de maneira mais marcante, no enquadramento do multiculturalismo intelectual americano. No entanto, o conto de Butler, da mesma forma que o trabalho de Atwood, insere nosso planeta em um quadro distópico aliado a problemas sócioambientais, como a própria destruição do ecossistema.

[... In 1979 the Three Mile Island nuclear power plant had a near meltdown, contaminating the immediate area with radioactive waste. In 1984, a large hole in the earth's protective ozone layer was discovered over Antarctica, caused by decades of pollution. In the 1980s many communities began recycling programs and there were visible protests 
of the development of rain forests and other wilderness areas, reflecting awareness of the relationship between the actions of individuals and the life of the planet [...]

[...] "Bloodchild" may be interpreted as a parable about the sacrifices and satisfactions of living in a multicultural society. Multiculturalism - the recognition and appreciation of cultural differences that exist within a larger society - became a catchword in the 1980s [...] (http:// www.answers.com/topic/bloodchild-story-6) [ [...] Em 1979, a usina nuclear de Three Mile Island teve um acidente extremamente sério, contaminando a área imediata com lixo radioativo. Em 1984, um buraco grande na camada de ozônio que protege a Terra foi descoberto acima da Antártica, causado por décadas de poluição. Nos anos 1980 muitas comunidades começaram programas de reciclagem e ocorreram protestos visíveis contra a implantação do desenvolvimento urbano em florestas tropicais e em outras áreas silvestres, refletindo a consciência da relação entre as ações de indivíduos e a vida do planeta (...)] (...) "Bloodchild" pode ser interpretado como uma parábola sobre os sacrifícios e satisfações de viver em uma sociedade multicultural. Multiculturalismo - o reconhecimento e a consideração de diferenças culturais que existem dentro de uma sociedade maior - é uma palavra que se tornou um estribilho nos $\operatorname{anos} 1980[\ldots]$ ]

O entendimento de "Bloodchild" como parábola nos remete às suas associações com tradicionais histórias do folclore infantil, associações essas que, como já vimos, podem ser também aplicadas a O Conto da Aia; no entanto, como há a reversão dos papéis tradicionais de gênero, no caso da obra de Butler, é a fêmea Tlic que pode ser associada à figura do mal: 
Há um momento em que T Gatoi, "sondando" o jovem (o que ocorre na noite da implantação de seus ovos em Gan) com "seis ou sete de seus membros", lhe diz: "Você está finalmente engordando. A magreza é perigosa", ao que sua mãe se contrapõe, dizendo "duramente": Ele ainda está magro demais"(BUTLER, 1996, p. 4). Isso não pode deixar de sinistramente lembrar a bruxa malvada de João e Maria, quando ela pede para ver o dedo mindinho das crianças a fim de saber se já estão gordinhas o suficiente para que delas possa se alimentar (DE LA ROCQUE, 2006, p. 77).

Enquanto temos em Atwood a figura feminina submetida em todos os seus aspectos: social, econômico e moral, Butler configura o ser feminino como aquele que precisa ser preservado para gerar vida (as fêmeas humanas), e também, mesmo se valendo de outra espécie, como ser dominante e que submete. T"Gatoi, a oficial inseto, é uma fêmea forte e poderosa tanto em caráter quanto no físico, e seu ferrão, que tanto pode causar prazer quanto dor, possui uma simbologia fálica. Já Offred, a Aia, é mais fraca e seu único instrumento de poder consiste na possibilidade de ser capaz de gerar em seu próprio ventre uma vida, ainda que ela mesma seja somente uma espécie de portadora desta vida - exatamente como os homens em "Bloodchild".

Atwood dá voz àquelas que se submeteram ou foram submetidas por falta de opção, não só em $O$ Conto da Aia, mas em outras obras, tais como as escravas gregas e a própria Penélope, protagonista em Odisséia de Penélope (ATWOOD 2005). Butler descreve o clima discriminatório em que viveu e o coloca em xeque, ao escrever "Bloodchild", potencializando o papel do ser diferente, o inseto fêmea, dominante e capaz de manipular as sensações de dor e prazer, naquele que era o submetido, o próprio homem. Aqui vale a pena descrever a cena da implantação dos ovos de T'Gatoi em Gan:

[...] eu me despi e me deitei do lado dela. Eu sabia o que fazer, o que esperar. Haviam me contado, 
durante toda a minha vida. Eu senti o ferrão familiar, narcótico, uma sensação agradável. Depois, foi a vez do tatear cego do seu ovipositor. A perfuração foi indolor, fácil. Tão fácil, a entrada...Ela ondulou contra meu corpo, seus músculos forçando seu ovo do seu corpo para o meu (BUTLER, 1996, p. 27).

Elyce Era Helford (apud WHYTE, 2007) também vê a poderosa Tlic desempenhando o que seria um amálgama de papéis que, na sociedade humana, pertenceriam tanto ao gênero masculino (o de líder político) quanto ao feminino (a proteção dos humanos da exploração excessiva pelos Tlic, já que ela faz parte do grupo dominante que valoriza a formação das "famílias" de Tlic e humanos, em oposição ao que quer tratar os últimos simplesmente como animais hospedeiros irracionais). Acreditamos que a concepção do macho como componente ativo no engravidamento da fêmea passiva - chegou-se inclusive a crer, por séculos, que a mulher só contribuiria com o útero como recipiente, o que ironicamente pode de fato chegar a ocorrer com as novas tecnologias reprodutivas (LE BRETON, 2007) que Butler tão eficazmente inverte em "Bloodchild", está embutida não somente em noções populares, como também na própria construção da ciência moderna. Conforme Emily Martin explica (MARTIN, 1991), a ciência certamente não tem se furtado a dar sua sacrossanta contribuição para a manutenção desse infeliz contraste, que permanece tão eficaz também por permear a distinção entre os gêneros desde sua origem aparentemente mais remota.

A questão de gênero torna-se muito mais complexa quando sofre as imbricações no que diz respeito à questão da maternagem. Se em Atwood, com já dissemos, o masculino submete o feminino; em Butler, temos o reverso do quadro de forma extrema e, em ambas as obras, a posição do ser que pare em relação à criatura parida, é diametralmente diversa. 
Pesquisas históricas mencionam a questão da frieza e da indiferença inicial dos pais para com a pequena criatura, que era simplesmente, muitas vezes, entregue a amas-de-leite, praticamente abandonada com as mesmas, o que frequentemente resultava em que não chegasse nem mesmo ao primeiro ano de idade (BADINTER, 1985). Nas obras analisadas, o fruto é encarado de duas formas. Em Atwood, praticamente não há escolha: as mulheres, no caso, as Aias, são vistas como matrizes, meras reprodutoras, com a tendência de encarar o filho como o resultado de uma obra, um trabalho, uma missão a que foram designadas. Todavia, esse sentimento de "obrigação moral" imposta pelo Estado de Gilead não apagava o amor pelo fruto gerado. Esse amor poderia ser traduzido de duas formas: ou através do estado de instabilidade mental a que algumas ficavam submetidas ou da rebeldia ao que lhes era imposto.

Na obra de Butler, esse sentimento não procedem, pois a posição dominante feminina coloca como implícito o fato de que os frutos, no caso as larvas, permanecerão sob os cuidados da mãe, e não do hospedeiro, que também obviamente não tem nenhum interesse nos pequenos seres que, se não forem removidos a tempo, poderão inclusive devorá-lo... Assim, a atenção maior parece voltada para o foco da sobrevivência de ambos: larvas e hospedeiros, garantindo a manutenção do corpo masculino para uma próxima leva de ovos.

Nas duas obras, a figura masculina e a feminina possuem, de certa forma, um papel igualmente importante: ambos os gêneros são repositórios de vida, humana ou não, e garantem a sobrevivência de uma espécie. Por outro lado, Butler faz uma subversão quanto ao surgimento de vida: esta, de certo modo, se origina de um ventre masculino. Segundo a mitologia, Atena, deusa da guerra e da razão, nasceu, já em armas, de uma cabeça masculina e seus atributos e características estão diretamente ligadas ao caráter viril, contrapondo cabeça e ventre, masculino e feminino. 
Nascer da cabeça do homem significa também marcar, desde o início, uma preferência. A deusa da Razão privilegia, desde o seu primeiro dia, a forma de produção que vem da cabeça - e dos homens em oposição à produção que vem do corpo - e das mulheres (GAGNEBIN, 2005, p. 37).

\section{Considerações Finais}

As obras de Margaret Atwood e de Octavia Butler nos remetem a questões bastante pertinentes: à complexidade das análises entre sexo e gênero, feminino e feminista, domínio e submissão. Poderíamos dizer que os conceitos sofrem uma confluência e se intercalam de forma quase indelével, a ponto de mascarar cada um dos sentimentos ali expostos.

O dominante e o submetido precisam um do outro para que seus papéis sejam caracterizados de forma a merecerem seus rótulos. A submissão pode ser permeada por vários fatores, tais como a conveniência e a justificativa da auto-imobilidade diante de uma situação. Assim também o discurso feminino pode tomar ares de autosuficiência, quando exacerba seu clamor.

Todo esse emaranhado de conceitos e questões em torno dos aspectos controvertidos, suscitado pela leitura da ficção científica de veio feminista, nos serve para lembrar que a antiga e confortável fronteira entre "o natural" e "o artificial" vem sendo progressivamente elidida. Matizes culturais, adicionados ao pano de fundo biológico, justificaram a relegação das mulheres à posição de meras reprodutoras da espécie humana, "cálices sagrados" onde seriam gerados os homens, ou seja, os verdadeiros motores da sociedade.

A complexidade entre gênero e sexo é bem colocada por Judith Butler, que repensa gênero como um verbo e não um substantivo:

[...] gênero não é um substantivo, mas também não é uma série de atributos vagos, pois vimos que o 
efeito substancial do gênero é performativamente produzido e obrigado pelas práticas reguladoras da coerência de gênero. Assim, no discurso herdado da metafísica da substancia, o gênero prova ser performativo - isto é, constituindo a identidade que se propões que ele seja. Neste sentido, gênero é sempre um ato, embora não um ato feito por um sujeito que possa ser considerado como preexistindo o ato. (BUTLER, 1990, p. 24-25)

Não podemos, logicamente, concluir um assunto cuja discussão tem acompanhado a mulher ao longo dos tempos e ainda o será por muitos anos. No entanto, vale a pena resgatarmos, aqui, o pensamento de Anzaldúa, quando coloca que o feminismo trouxe em seu bojo a linguagem das mulheres burguesas, calando um grupo que não pertenceria a esta classe e só com o surgimento das escritoras não brancas e com opção sexual diferente, nos anos 80 , foi possível uma mudança de cenário, dando voz a este outro grupo:

[...] muitas de nós - mulheres de cor que dependuramos diplomas, credenciais e livros publicados ao redor dos nossos pescoços, como pérolas às quais nos agarramos desesperadamentearriscamos estar contribuindo para a invisibilidade de nossas irmãs escritoras [...]

[...] Como nos atrevemos a sair de nossas peles? Como nos atrevemos a revelar a carne humana escondida e sangrar vermelho como os brancos? É preciso uma enorme energia e coragem para não aquiescer, para não se render a uma definição de feminismo que ainda torna a maioria de nós invisíveis. (ANZALDÚA, 2000, p. 231) 


\section{Referências}

ANZALDÚA, Gloria. Falando em línguas: uma carta para as mulheres escritoras do terceiro mundo. Revista Estudos Feministas, Centro de Filosofia e Ciências Humanas - UFSC, v.8, n.1, 2000, pp.229-236.

ATWOOD, Margaret. A Odisséia de Penélope. São Paulo: Companhia das Letras, 2005.

ATWOOD, Margaret. O Conto da Aia. Rio de Janeiro: Editora Rocco, 2006.

BADINTER, Elizabeth. Um amor conquistado-o mito do amor materno. Rio de Janeiro: Editora Nova Fronteira, 1985.

BARR, Marleen S. Lost in Space: Probing Feminist Science Fiction and Beyond. Chapel Hill: The University of North Carolina Press, 1993.

BOOKER, M. Keith. Dystopian Literature: a theory and research guide. Westport, Connecticut: Greenwood Press, 1994.

BUTLER, Judith. Gender trouble- Feminism and the subversion of identity. London and New York: Routledge, 1990.

BUTLER, Octavia. Bloodchild. In: Bloodchild and Other Stories. New York: Seven Stories Press, 1996, p.3-32.

BUTLER, Octavia. The Evening and the Morning and the Night. In: Bloodchild and Other Stories. New York: Seven Stories Press, 1996, p. 35-70;.

CARDOSO, Ciro Flamarion. Ficção científica, percepção e ontologia: e se o mundo não passasse de algo simulado? História, Ciências, Saúde - Manguinhos, vol.13 supl.0 Rio de Janeiro p. 17-37, 2006. 
DE LA ROCQUE, Lucia. Imbricações entre gênero e ciência. Em The Evening and the Morning and the Night, de Octavia Butler. In: GAZZOLA, Ana Lúcia, GOULART DE ALMEIDA, Sandra, e LIMA DUARTE, Constância, (Eds). Gênero e representação em literaturas de língua inglesa. Col. Mulher \& literatura, V. 4. Belo Horizonte: Ed. UFMG, 2002, pp. 61 - 68.

DE LA ROCQUE, Lucia. Gênero e reprodução em questão: utopias e distopias feministas. In: ARAÚJO JORGE, T. (Ed.). Ciência e Arte: encontros e sintonias. Rio de Janeiro: Senac Rio, 2004, pp. 48-66.

DE LA ROCQUE, Lucia. Entre a natureza e a cultura: gênero, ciência e poder em "Bloodchild", de Octavia Butler. In: SALGUEIRO, M. A. (Ed.) Feminismos, identidades comparativismos: vertentes nas literaturas de língua inglesa. Vol 4. Rio de Janeiro: Editora Europa, 2006, pp 71-82.

DERY, Mark. Negro para o futuro: Afrofuturismo1. 0. Disponível em: http://www.rizoma.net/ interna.php?id=148\&secao=afrofuturismo. Acesso em Outubro de 2007.

FERNANDES, Fabio. O fim de uma era.Disponível em: http:// www.cibercultura.org.br/tikiwiki/tikiread_article.php?articleId=56. Acesso em Outubro de 2007.

GAGNEBIN, Jeanne Marie. Sete aulas sobre linguagem, memória e história. Rio de Janeiro: Imago Editora, 2005.

GONZALES, Juan. Science Fiction Writer Octavia Butler on Race, Global Warming and Religion. Disponível em: http:// www.democracynow.org/2005/11/11/science_fiction_writer_ octavia_butler_on Acesso em Setembro de 2007.

HAYNES, Roslynn D. From Faust to Strangelove: Representations of the Scientist in Western Literature. Baltimore and London: The John Hopkins University Press, 1994. 
INGERSOL, Earl G. (Org.) Margaret Atwood: Conversations.

Princeton, New Jersey: Ontario Review Press, 1990.

LE BRETON, David. Adeus ao corpo: antropologia e sociedade. São Paulo: Papirus, 2007.

MARTIN, Emily. The egg and the sperm: how science has constructed a romance base on stereotypical male-female roles. Signs: Journal of women in culture and society, 16 (3): p. 485501, 1991.

MOYLAN, Tom. Scraps of the untainted sky: science fiction, utopia, dystopia. Boulder, Colorado: Westview Press, 2000.

SCHOLES, Robert. Structural fabulation. Notre Dame, Indiana: University of Notre Dame Press, 1975.

SONTAG, S. Mulheres. In: Jornal O Estado de São Paulo, Caderno 2 p.D9, de 8 de janeiro de 2000.

VERNANT, Jean Pierre. O homem grego. Lisboa: Editorial Presença, 1994.

WILSON, Sharon Rose. Margaret Atwood's Fairy Tale Sexual Politics. Jackson: University of Mississipi Press, 1996.

WHYTE, Nicholas. Review of "Bloodchild" by Octavia Butler. Disponível em: http://explorers.whyte.com/sf/bch.htm. Acesso em novembro de 2007

Obs.: a responsabilidade das traduções é das autoras do artigo em questão. 